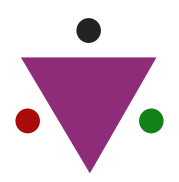

IJCRR

Section: Healthcare

Sci. Journal Impact

Factor: 6.1 (2018)

ICV: 90.90 (2018)

(c) (7) (3)

Copyright@IJCRR

\section{The Study Protocol of Comparative Study on Efficacy of Marma Chikitsa, Agnikarma and Physiotherapy in Avabahuka (Frozen shoulder)}

\author{
Amol Deshpande ${ }^{1}$, Priti Desai ${ }^{2}$, Mayuri Deshpande ${ }^{3}$, Sonali Choudhary ${ }^{4}$, \\ A. R. Narkhede ${ }^{5}$
}

'Assistant Professor, Department of Rachana Sharir, Mahatma Gandhi Ayurved College, Hospital \& Research Centre, Datta Meghe Institute of Medical Sciences (Deemed to be University), Wardha, Maharashtra, India; ${ }^{2}$ Professor and Head, Department of Rachana Sharir, Mahatma Gandhi Ayurved College, Hospital \& Research Centre, Datta Meghe Institute of Medical Sciences (Deemed to be University), Wardha, Maharashtra, India; ${ }^{3}$ Assistant Professor, Department of Kayachikitsa, Mahatma Gandhi Ayurved College, Hospital \& Research Centre, Datta Meghe Institute of Medical Sciences (Deemed to be University), Wardha, Maharashtra, India; 4Professor, Department of Community Medicine, Jawaharlal Nehru Medical College, Datta Meghe Institute of Medical Sciences (Deemed to be University), Wardha, Maharashtra, India; ${ }_{5}^{5}$ Professor, Mechanical Engineering, Yeshwantrao Chavan College of Engineering, Nagpur, Maharashtra, India.

\title{
ABSTRACT
}

Background: Frozen shoulder or adhesive capsulitis is a disease that usually occurs between the age group of 40-70 years; the females and diabetic patients more prone to the disease. Physiotherapy and Agnikarama are the commonest modalities used for the treatment of this disease in contemporary science and Ayurveda respectively. The traditional Vaidyas, Nadi Vaidya and bonesetters are commonly practising another modality called Marma Chikitsa, however, the literature regarding this is very sparse.

Objective: To compare the efficacy of Marma Chikitsa, Agnikarma and physiotherapy in Avabahuka.

Methods: 150 patients of Avabahuka (frozen shoulder) will be randomly allotted to three groups having 50 patients in each. Group A will be treated with the Marma Chikitsa for the alternate day. Group B will be treated with the Agnikarma, which will be repeated after 7 days, such three settings will be done. Group C will be treated with the physiotherapy for 15 continues days which shall include Ultrasound, TENS and Exercise for a range of motion (ROM). Statistical Analysis will be done after the last visit of the patient for the anticipative outcome by using Paired t-test, Unpaired t-test and one way ANOVA tests.

Results: We anticipate that Marma Chikitsa may have a better outcome as compared to Agnikarma and Physiotherapy.

Conclusion: Marma Chikitsa will be the new inclusion in the therapeutic model of Avabahuka and also can be studied in different musculoskeletal disorders

Key Words: Agnikarma, Avabahuka, frozen shoulder, Marma Chikitsa, Physiotherapy

I.E.C. approval: DMIMS(DU)/IEC/Sept-2019/8334 (01/10/2019)

\section{INTRODUCTION}

Frozen shoulder means a significant loss of its range of motion in all direction (capsular pattern). It's a result of inflammation, scarring, thickening and shrinkage of the capsule that surrounds the normal shoulder joint. ${ }^{1}$ It is also called as Adhesive Capsulitis and is one of the most common causes of shoulder pain and disability. The worldwide prevalence of the frozen shoulder is $2 \%$ to $3 \%$. It usually occurs between $40-70$ years of age. Females are more prone to diseases than male. ${ }^{2}$ The incidence of frozen shoulder is 2-4 times higher in diabetes than

\section{Corresponding Author:}

Dr. Amol Madhav Deshpande, Mahatma Gandhi Ayurved College, Hospital \& Research Centre, Datta Meghe Institute of Medical Sciences (Deemed to be University), Wardha, Maharashtra, India; Contact: 91-9146131519; Email: deshpandeamol86@gmail.com

ISSN: 2231-2196 (Print)

ISSN: 0975-5241 (Online)

Received: 05.09.2020

Revised: 12.10 .2020 the general population. ${ }^{3}$ Frozen shoulder is divided into two types as per their cause Primary and Secondary; Primary frozen shoulder has insidious onset usually without any known aetiology, while the secondary frozen shoulder is due to the clinical conditions like rheumatoid arthritis, osteoarthritis, trauma or immobilization has three stages, freezing (Painful), Frozen (Adhesive) and thawing. Though it is not a life-threatening disease, it causes problems in day to day activities, thus affecting the quality of life. ${ }^{1,2}$

Considering the signs and symptoms, of frozen shoulder, In Ayurveda, it can be correlated with Avabahuka. Avabahuka 
is mentioned in almost all compendia under the heading of Vatvyadhi. Acharya Sushruta first time coined the term Avabahuka in Nidansthan. ${ }^{4}$ Acharya Sharangdhar mentioned it in Vataj Nanatmaja Vyadhi. ${ }^{5}$ In this disease Siraaakunchana (a contraction of Tendons) is a common symptom as per Sushruta. ${ }^{4}$ Bahushosh ${ }^{5}$ (wasting muscles of arm), and Amsa Bandhanshosh (a contraction of shoulder ligaments) ${ }^{4}$ (a contraction of shoulder ligaments)are the other symptoms mentioned in different texts. There are several approaches regarding the treatment of this disease like Agnikarma, ${ }^{7}$ Physiotherapy, ${ }^{8}$ and Marma Chikitsa. ${ }^{9}$

Agnikarma is indicated for pain management in the diseases of Sira Snayuagat vat.$^{10}$ Avabahuka is related to Sira and Sn$a y u,{ }^{11}$ as the disease caused by Sankoch (Contraction) of Sira and Snayu. In modern medicine, physiotherapy and exercises are considered as a first-line treatment for frozen shoulder. ${ }^{8}$ Physiotherapy management aims to relieve pain, promote healing reduce muscles spasm, increases joint range of motion (ROM) and strength. ${ }^{12}$

Marma Chikitsa is one of the treatment modality used by the traditional Vaidyas, Nadi Vaidya and bonesetter in Avabahuka. Several studies have been published regarding the effect of Agnikarma and Physiotherapy, but literature about the studies on Marma Chikitsa is very sparse. Marma Chikitsa is nothing but the stimulation of the Marma points related to the affected areas. Avabahuka is the disease-related with the Amsa (Shoulder) region ${ }^{4}$ and has restricted movement of the upper limb. Marma related with the upper limbs i.e Kshipra, Manibandha, Kurpar, Indrabasti Aani, Bahavi are stimulated in Marma Chikitsa. The scientific explanation behind the Marma Chikit$s a$ is still obscure, hence this study is aimed to generate evidence towards the efficacy of Marma Chikitsa in Avabahuka and its comparison with an Agnikarma and physiotherapy.

Agnikarma, Physiotherapy and Marma Chikitsa are the three different techniques used for the treatment of Avabahuka (Frozen Shoulder). Agnikarma and Physiotherapy have several contraindications viz. Agnikarma procedure is contraindicated in Pitta Prakruti, Child, Old age, those having multiple wounds, and in Grishma Rutu (Summer Season). Also, it leads to many complications if not performed properly. ${ }^{13}$ Similarly, Physiotherapy requires different instruments, which are more costly and is time-consuming. However, Marma Chikitsa is cost-effective with minimal complications; moreover, it can also be performed by the patients if they are trained to stimulate the Marmas as a self Marma therapy.

\section{MATERIALS AND METHODS}

\section{Study design}

The study will be the Randomized Controlled trial in which diagnosed patient of Avabahuka will be equally distribut- ed to three groups. Marma therapy will a study group and Physiotherapy and Agnikarma will be considered as control groups.

\section{Participants}

The study will be instigated at Mahatma Gandhi Ayurved College, Hospital and Research Centre, Salod (H), Wardha and Ravi Nair physiotherapy college, Sawangi Wardha. A total of 150 patients will be enrolled and distributed evenly into the three groups by random sampling. The groups will be as follows

Group A (Study Group): Marma Chikista with Placebo.

Group B (Control Group): Agnikarma with Placebo.

Group C (Control Group): Physiotherapy with Placebo

\section{Inclusion and Exclusion Criteria}

Inclusion criteria - a) All subjects irrespective of sex-having age between 20 to 60 years, b) Patient having classical symptoms of Avabahuka, c) Patient fit for Agnikarma and Marma Chikitsa

Exclusion criteria - a) Age group less than 20 and exceeding 60 shall be excluded. b) Patient has a history of Trauma at the affected limb.

\section{Recruitment}

Subjects who are eligible for Agnikarma, Physiotherapy and Marma Chikitsa and fulfilling inclusion criteria willing to give written consent will be enrolled for the study. The selected subject will be informed about the study, possible outcome and side effects of intervention if any. Subjects will be selected based on inclusion and exclusion criteria.

\section{Assessment}

Assessment will be done based on the subjective and objective parameters. In subjective parameters, Shool (Pain), Stiffness will be seen and in objective parameters, Mid Arm circumference and range of Motion (ROM) will be measured. The pain will be assessed through Visual Analogue Scale (VAS) and stiffness will be calculated based on gradation 0 to 3 where 0 is No stiffness and 3 is severe stiffness. Pre and post-treatment mid-arm circumference will be calculated. Methods of measurement of angles of the shoulder joint to determine the range of motion of the shoulder joint are as follows

I. Flexion

The angle of Flexion will be recorded in the supine position in such a way that arm is placed at the side of the body with palm pointed at medial side. This position will be considered as 0 degrees. Then fulcrum will put on acromial process, stationary and moving arm of the goniometer will align with the midline of the humerus 
and lateral epicondyle then flex the shoulder joint by moving the arm straight above the head.

II. Extension

The angle of the extension will be recorded in the prone position in such way that arm is placed at the side of the body with palm pointed at medial side. This position will be considered as 0 degrees. Then fulcrum will put on the acromial process, stationary and moving arm of the goniometer will align with the midline of the humerus and lateral epicondyle. Then extend the shoulder joint by moving the arm backwards by keeping elbow joint slightly bent. Moving arm of the goniometer will be moved with the arm and then the angle between the stationary and moving arm will be calculated

III. Abduction

The angle of the abduction will be recorded in the supine position in such a way that arm is placed at the side of the body with palm pointed anteriorly. This position will be considered as 0 degrees. Then fulcrum will be pleased on the acromial process, stationary and moving arm of the goniometer will be aligned with the anterior midline of the humerus. Then move the upper limb away from the midline in the coronal plane by keeping the elbow straight. Moving arm of goniometer will move with the arm and then the angle between the stationary and moving arm will be calculated

IV. Adduction

The angle of the abduction will be recorded in the supine position in such a way that arm is placed at the side of the body with palm pointed anteriorly. This position will be considered as 0 degrees. Then fulcrum will be pleased on the acromial process, stationary and moving arm of the goniometer will be aligned with the anterior midline of the humerus. Then move the upper limb towards the midline in the coronal plane by keeping the elbow straight. Moving arm of goniometer will move with the arm and then the angle between the stationary and moving arm will be calculated

V. Internal Rotation

The angle of the internal rotation will be recorded in supine positions in such a way that elbow is flexed by 90 degrees and shoulder is abducted by 90 degrees with palms are towards the anterior side. Humerus should be parallel to the floor. This position will be considered as 0 degrees. Fulcrum will be kept at olecranon process centrally, here moving and stationary arm are at different positions, moving arm is aligned with the styloid process of the ulna and stationary arm should be perpendicular to the floor. Then move the forearm backward as much as the patient can, Moving arm of the goniometer is move with the arm and then the angle between the stationary and moving arm will be calculated

VI. External Rotation

The angle of the external rotation will be recorded in a supine position which is same as an internal rotation that is elbow is flexed by 90 degrees and shoulder is abducted by 90 degrees with palms are towards anterior side. Humerus should be parallel to the floor. This position is considered as 0 degrees. here moving and stationary arm are at different positions, moving arm is aligned with the styloid process of the ulna and stationary arm should be perpendicular to the floor. The only difference is that here movement the forearm is forward as much as the patient can, Moving arm of the goniometer is move with the arm and then the angle between the stationary and moving arm will be calculated

\section{Intervention Plan}

The total duration of the intervention will be the same for all groups which will be for 15 days but the follow up will be different in all groups as per their indications (Table 1)

\section{Table 1: Detail intervention plan}

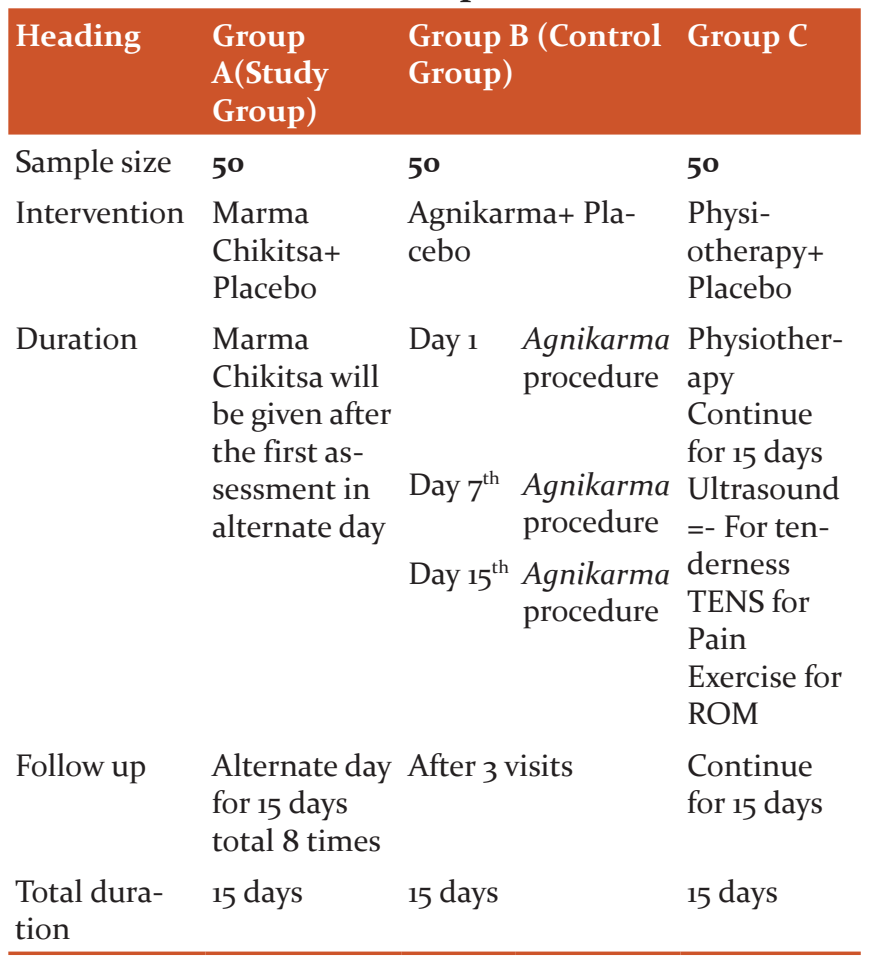

\section{Procedure of Agnikarma:}

\section{Pre-procedural method:}

- Consent will be taken regarding the procedure.

- The appropriate position will be given to the patient in a chair, or sitting or lying on a bed.

- Point of maximum pain will be marked by the marker.

\section{Procedural method:}

- By using the Gas Burner Agni Shalaka (Copper) will be heated up to Red Hot colour

- $\quad$ Red Hot Shalaka will be placed over the Marked area up to the Samyakdagdha Sign

- The procedure will be conducted in a doted manner. 


\section{Post-procedural method:}

- After the procedure, Fresh Alovera Pulp will be applied over Agnikarma Area

- Placebo capsule twice a day after the meal will be given for 15 Days as a placebo

- The procedure will repeat after 7 days

\section{Procedure of Marma Chikitsa}

\section{Pre-procedural method:}

- Consent will be taken regarding the procedure

- The patient will be kept in Supine Position,

\section{Procedural method:}

- Site of the Marma, Kshipra, Manibandha, Indrabasti, Kurpur, Aani and Bahavi will be identified

- Each Marma will be stimulated by pressing it for 15/16 times for 1 second.

- This procedure will be repeated thrice with resting 5 min in between.

- Placebo capsule twice a day after the meal will be given for 15 Days as a placebo.

- The procedure will repeat after 7 days.

\section{Procedure of Physiotherapy}

\section{Pre-procedural method:}

- Consent will be taken regarding the procedure

- The appropriate position will be given to the patient in a chair, or sitting or lying on a bed.

\section{Procedural method: ${ }^{1}$}

Three techniques will be used in this procedure

- Ultrasound - for tenderness, ultrasound of continuous mode at $1 \mathrm{MHz}, 2 \mathrm{w} / \mathrm{cm} 2$ for 4 minutes to shoulder joint

- TENS- for Pain Management, low rate high-intensity TENS for 20 minutes

- Mobilization Exercises for-ROM

- Placebo capsule twice a day after meal for 15 Days as a placebo

\section{Randomization procedure}

Concerning suitability of the patient for enrollment in the study, the participants will be allotted randomly by a computer generated table method either for Marma Chikitsa, physiotherapy or Agnikarma.

\section{Methods of data analysis}

The sample size was calculated based on a type I error of 5\% (i.e., $\mathrm{P}<0.05$ ) with the help of a statistician. Using formal sample size calculations, the sample size is found 50 patients for each group. Statistical analysis will be carried out by institutional statistician. Statistical assessment will be done through Paired t-test, Unpaired t-test and one-way ANOVA

\section{RESULTS}

We anticipated that Marma Chikitsa had better outcome as compared to the Agnikarma and Physiotherapy and if it is shown, it can be the cost-effective modality without any side effect for the patient of Avabahuka and which will be again studied in various musculoskeletal disorders as a different treatment modality

\section{DISCUSSION}

Marma Sharir is a unique concept of paramount significance in Ayurved Rachana Sharir. The evidence-based literature on Marma Chikitsa is very sparse. Marma Chikitsa plays an important role, especially in Musculoskeletal disorders. Article related to arthritis and arthropathies of different joints with allopathic remedies is available. ${ }^{14-16}$ Work-related and Sports related musculoskeletal morbidities have been reported..$^{17,18}$ Pertaining the frozen shoulder the commonest modality used in Physiotherapy and Agnikarma. ${ }^{19-21}$ The action of Agnikar$m a$ in various musculoskeletal disorders is also reported. ${ }^{22}$ It has been observed that Marma Chikitsa though beneficial, not studied in frozen shoulder. On extensive literary search, the only single study on Marma Chikitsa in the frozen shoulder was found, but in that study, they were not compared Marma Chikitsa with any other modalities which are used in these days. Also, the proper mode of action is not explained. Hence, this study is proposed to generate the conventions regarding Marma therapy and its efficacy with other modalities in the management of Avabahuka.

\section{CONCLUSION}

The Marma Chikitsa with present methodology is a will be the new, easy and cost-effective procedure for the patient of Avabahuka as compare to Agnikarma and physiotherapy.

\section{Financial disclosure}

The study partly funded by Datta Meghe Institute of Medical Sciences (Deemed to be University), Wardha.

\section{ACKNOWLEDGMENT}

Authors acknowledge the immense help received from the scholars whose articles are cited and included in references to this manuscript. The authors are also grateful to authors / editors / publishers of all those articles, journals, and books from which the literature for this article has been reviewed and discussed.

\section{Conflict of Interest: Nil}

Source of Funding: Nil 


\section{REFERENCES}

1. Baig MO, Baig UA, Naseem A. Pain Modulation in Frozen Shoulder by Electrotherapy Versus Exercise Therapy. Anna King Edw Med Uni 2011;17(3):245.

2. Chokkalingam M, Saradha S, Navitha A, Nayar PG. Incidence and clinical profile of patients with a frozen shoulder after cardiac surgery. J Clin Prevent Cardiol 2017;6(4):142.

3. Inayat F, Ali NS, Shahid H, Younus F. Prevalence and determinants of frozen shoulder in patients with diabetes: a single center experience from Pakistan. Cureus. 2017;9(8):e1544.

4. Acharya YT. Sushrut Samhita, Nidanstha, Chapter 1/82, Chaukhamba Surbharti Prakashan, Varanasi, p. 269.

5. Tripathi B. Sharangdhar Samhita, Purvkhanda, 7/108, reprint 2008, Choukhamba Sanskrit Pratishthan, Varanasi, 2012; 108.

6. Acharya YT. Charak Samhita, Chikistasthan, Chapter 28/98, reprint 2013, Chaukhamba Prakshan, Varanasi, 2013; 621.

7. Kumar V, Tukaram SD, Gupta SK, Mahanta VD. Role of agnikarma in degenerative disorder wsr Avabahuka (Frozen shoulder)-case study. Ancient Sci Life 2012;32(1):S31.

8. Chan HB, Pua PY, How CH. Physical therapy in the management of frozen shoulder. Singapore Med J 2017;58(12):685.

9. Prasad S, Ranjan VR, Vishwakarma SK, Rao R, Rani DR. Clinical Evaluation of Marma Therapy in Avabahuka WSR to Frozen Shoulder. JMSCR 2017;05(05):22411.

10. Acharya YT. Sushrut Samhita, Sutrasthan, Chapter 12/10, Print 2012, Chaukhamba Surbharti Prakashan, Varanasi, 2012; 52

11. Paradkar H. Ashatanghruday, Nidansthan, Chapter $15 / 43$, reprint 2010, Cahukhamba Surbharti Prakashan, Varansi,2010; 534

12. Sigh H, Goyal M. Physiotherapy management of adhesive capsulitis: A review of literature. Int J Physiother Res 2016; 4 (6): 1719.
13. Acharya YT. Sushrut Samhita, Sutrasthan, Chapter 12/14, Print 2012, Chaukhamba Surbharti Prakashan, Varanasi, p. 52.

14. Kumar S, Garikapatti A, Andhale A, Nayak A. Cryptogenic Organising Pneumonia as Main Presenting Feature of Rheumatoid Arthritis. J Clin Diagn Res 2019;13(11).

15. Morey AD, Madke BS, Singh A, Singh S, Kulkarni S. Response to Infliximab Biosimilar in a Case of Reactive Arthritis: Our Experience. J Clin Diagn Res 2019;13(12):WL01.

16. Somani R, Panda P, Dungarwal M, Gupta S, Kawde P. Idiopathic Charcot's Arthropathy of Ankle Joint: A Rare Case. J Clin Diagn Res 2019;1;13(3).

17. Khanam N, Wagh V, Gaidhane AM, Quazi SZ. Assessment of Work-Related Musculoskeletal Morbidity, Perceived Causes and Preventive Activities Practiced to Reduce Morbidity Among Brick Field Workers. Ind J Comm Health 2019;31(2):213-219.

18. Kurhade G, Nayak BS, Kurhade A, Unakal C, Kurhade K. Effect of martial arts training on IL-6 and other immunological parameters among Trinidadian subjects. J Sports Med Phys Fit 2018;58(7-8):1110.

19. Goyal C, Naqvi WM, Sahu A. An atypical case of febrile infection-related epilepsy syndrome following acute encephalitis: impact of physiotherapy in regaining locomotor abilities in a patient with neuroregression. Pan Afric Med J 2020;36.

20. Risaldar P, Raut A, Bawiskar D, Naqvi WM. Impact of Physiotherapy Rehabilitation Program on Postoperative Acl Tear Patient on Prognosis Leading to Maintain Consistency in Sport. Int J Res Pharmaceu Sci 2020;11(3):4821.

21. Sathe S, Khurana SK, Damke U, Agrawal PV. To Compare the Effects of Maitland Mobilization with Conventional Physiotherapy in Adhesive Capsulitis. Int J Cur Res Rev| 2020;12(14).

22. Rathod NA, Kuchewar VV. Review on the role of Agnikarma in the pain of various musculoskeletal disorders. J Indian Syst Med 2019;7(1):43. 